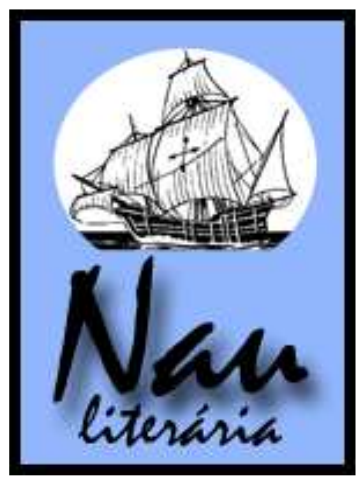

\author{
Simone Maria dos Santos Cunha** \\ Franciele Alves Amandio*** \\ Juracy Ignez Assmann Saraiva****
}

\begin{abstract}
Resumo: Este artigo comprova que os contos de Machado de Assis podem ser trabalhados de forma prazerosa com alunos de Ensino Médio. Os contos foram explorados por meio de roteiros de leitura cuja metodologia articula os estudos de língua e de literatura, partindo da leitura integral dos textos e fundamentando-se na Estética da Recepção. Os contos de Machado de Assis apresentam uma riqueza de significados que podem prender a atenção do leitor desde que sejam explorados em seus aspectos técnicocomposicionais e desde que sejam estabelecidas relações com o contexto dos leitores da atualidade. O trabalho atingiu seu objetivo, pois desenvolveu nos alunos o gosto pela leitura, o interesse em conhecer outras obras de Machado de Assis e a melhoria na escrita, demonstrando assim, que os textos do autor são fundamentais para o aprimoramento dos alunos do Ensino Médio.
\end{abstract}

Palavras-chave: Machado; leitura; contos; literatura; ensino.

\begin{abstract}
This paper proves that Machado de Assis' short stories can be worked in a delightful way with High School students. The short stories were explored through reading scripts whose methodology articulates language and literature studies, from the integral reading of the texts and supporting itself in the Aesthetic of Reception. Machado de Assis' short stories present a meaning richness that can fasten reader's attention since they are explored in their technical-compositional aspects and since there are relations established with the current readers' context. The work reached its aim, because it developed the students' reading taste, the interest in knowing other works by Machado de Assis and writing improvement, demonstrating thus, that the author's texts are fundamental for students improvement in High School.
\end{abstract}

Keywords: Machado; reading; short stories; literature; teaching.

O presente artigo discute a importância do ensino da literatura e apresenta uma experiência bem sucedida com alunos de Ensino Médio, baseada na aplicação de roteiros de leitura dos contos A cartomante e Pai contra mãe, ambos de Machado de Assis. A aplicação desses roteiros teve por objetivo estimular a prática da leitura, valorizar os contos de Machado

\footnotetext{
* Artigo desenvolvido no âmbito do projeto de pesquisa Concepções de literatura e leitura e sua inscrição na fiç̧ão machadiana,com apoio do CNPq e da FAPERGS.

** Graduada em Letras pela UNISINOS. Aluna do Mestrado em Processos e Manifestações Culturais na FEEVALE e Bolsista da CAPES no Projeto Concepções de Leitura e de Literatura na ficção machadiana.

*** Graduada em Letras pela UNISINOS. Bolsista do Projeto Concepções de Leitura e de Literatura na ficção machadiana na Universidade Feevale.

${ }^{* * * *}$ Pós-Doutora em Teoria Literária pela Universidade Estadual de Campinas. Coordenadora do Comitê Interdisciplinar da FAPERGS. Professora, pesquisadora da Universidade FEEVALE.
} 
e demonstrar que é possível trabalhar com os contos do autor de forma prazerosa. O trabalho iniciou com a leitura de A cartomante e sua comparação com Tílburi de praça, conto de Raul Pompéia; prosseguiu com a análise de Pai contra mãe e com o estabelecimento de suas relações intertextuais com o conto $O$ caso da vara. A proposta de trabalho foi desenvolvida de acordo com uma metodologia que articula os estudos de língua e de literatura, partindo da leitura integral dos textos e fundamentando-se na Estética da Recepção e que é explicitada por Juracy Assmann Saraiva ${ }^{1}$.

Os contos de Machado de Assis apresentam uma riqueza de significados que podem prender a atenção do leitor desde que sejam explorados em seus aspectos técnicocomposicionais e desde que sejam estabelecidas relações com o contexto dos leitores da atualidade. Assim, este artigo contempla três tópicos: a importância do ensino da literatura; a leitura de contos como alternativa na formação de leitores; uma proposta de roteiro de leitura de contos para o Ensino Médio.

\section{A importância do ensino da literatura}

Antonio Candido (2004) define a literatura como um bem incompressível a que todos têm direito e, por isso, defende a sua inclusão nos direitos humanos. Ele argumenta ainda que:

(...) há um conflito entre a idéia convencional de uma literatura que eleva e edifica (segundo os padrões oficiais) e a sua poderosa força indiscriminada de iniciação na vida, com uma variada complexidade nem sempre desejada pelos educadores. Ela não corrompe nem edifica, portanto, mas, trazendo livremente em si o que chamamos o bem e o que chamamos o mal, humaniza em sentido profundo, porque faz viver.

(CANDIDO, 2004, p.176)

Leyla Perrone-Moisés (2005) retoma a afirmação de Candido sobre a inclusão da literatura entre os direitos humanos e a complementa dizendo que, coincidentemente, em sua última aula no Collège de France, Roland Barthes também afirmou que "o direito à literatura deveria constar nos direitos humanos”. (PERRONE-MOISÉS, 2005, p.347) Ela discorre sobre as afirmações dos dois autores ao enfatizar a importância da literatura e discutir questões cruciais a respeito do ensino da literatura. Perrone- Moisés discute, por exemplo, o fato de o ensino de literatura de qualquer nacionalidade ser democrático e não elitista, uma vez que um livro é o mesmo, indiferente do tipo de papel no qual é publicado, conferindo, assim, acessibilidade a todos os alfabetizados, desde que estes possam contar com o auxílio do

\footnotetext{
${ }^{1}$ A autora expõe os fundamentos teóricos e a metodologia de exploração de textos literários nas seguintes publicações: Literatura na escola: propostas para o ensino fundamental e A sedução das narrativas aplicada ao estudo de contos machadianos, artigo publicado em Linguagem, sociedade e interação: reflexões teóricopráticas.
} 
professor, “a quem cabe apenas mostrar o objeto sob a sua melhor luz.”(PERRONE-MOISÉS, 2005, p.347) Ela argumenta que:

(...) o texto literário tem uma especificidade e um valor que devem ser preservados. Atualmente, há muita informação cultural circulando, o que não redunda em cultura, porque essas informações são superficiais, indiferenciadas, veiculadas sem nenhum critério de seleção e recebidas de modo aleatório. É como um antídoto a essa indiferenciação generalizada da informação que a literatura deve ser ensinada e estudada. A grande obra literária é meio de conhecimento, de crítica do real e exercício da liberdade imaginativa, sem a qual a história é vivida como fatalidade. $\mathrm{O}$ acesso às obras dotadas desses valores e ao instrumental que permite a sua melhor fruição é um direito ao qual corresponde um dever do professor e do crítico.

(PERRONE-MOISÉS, 2005, p. 347)

A autora também afirma que não tem sentido criar bibliotecas sem a escola preocuparse com a formação de leitores. E ainda complementa:

Ensinar literatura é ensinar a ler textos complexos. Sem leitura não há cultura. A pretensa democratização do ensino - a "Universidade para todos" - como nivelação baseada na "realidade" dos alunos redunda em injustiça social. O argumento de que se devem oferecer ao aluno apenas textos ao seu alcance, ou oriundos do seu ambiente social, é um paternalismo e um menosprezo da capacidade dos jovens. Ainda sobre o ensino da literatura, o que é subversivo hoje não é a militância política em sala de aula. O que é subversivo é ensinar poesia, pois, como diz Adorno, "qualquer que seja a sua temática, a poesia desvenda o fundamento qualitativo da sociedade." A grandeza da obra de arte é deixar falar aquilo que a ideologia dissimula.

(PERRONE-MOISÉS, 2005, p. 347)

A compreensão da importância que a literatura possui na vida do ser humano e do papel do professor na formação de leitores perpassa as academias, os cursos de formação de professores e as escolas. Entretanto, mesmo conhecendo o posicionamento de renomados estudiosos da literatura, muitos professores brasileiros reportam dificuldades no ensino da literatura e continuam utilizando o livro didático como recurso mais importante em suas aulas. Apesar de se constituir num recurso que pode ser utilizado nas aulas como mais um suporte para a aprendizagem, o livro didático não deve ser elemento central do ensino. De acordo com a citação acima transcrita, observa-se a necessidade de propiciar aos alunos o contato com o texto literário em si, e não com pequenos recortes deles apresentados em livros didáticos. Uma boa aula de literatura não pode, tampouco, centrar-se na listagem de tópicos e na memorização de datas da história da literatura, mas sim, centrar-se na apreciação das obras literárias.

No que diz respeito à análise de manuais voltados para o estudo da disciplina de Literatura, é possível encontrar uma preciosa crítica de Osman Lins sobre a utilização de trechos de obras literárias nesses livros. Por meio de suas palavras, é possível inferir que os autores desses manuais, ao utilizarem essas formas condensadas, acabam afastando o leitor do conhecimento das grandes obras. A atitude negligente evidenciada por ele acaba por não 
favorecer a divulgação da riqueza da literatura brasileira, pois não é possível ter acesso à complexidade e à consequente beleza de um texto literário sem conhecê-lo de forma integral:

A escolha dos fragmentos literários para esses compêndios vem sendo presidida pelo comodismo e pela rotina, pelo desconhecimento quase total de nossas letras, pela ausência completa do senso de valores e por um cabotinismo praticado impunemente, às escâncaras. Os autores de gramáticas, no Brasil, estão tornando cada vez menos conhecida a verdadeira literatura de nosso país.

(LINS, 1977 apud FREITAG; MOTTA; COSTA, 1989, p. 68-69).

Conforme Jauss: "Em todas as relações entre as funções, a comunicação literária só conserva o caráter de uma experiência estética enquanto a atividade da poiesis, da aisthesis e da katharsis mantiver o caráter de prazer.” (JAUSS, 1979, p.103). A poiesis é responsável pela adesão do leitor ao texto, o que permite que ele se transforme de um simples receptor num transformador do texto; a aisthesis possibilita a renovação da percepção de mundo do indivíduo, fazendo-o interagir com a realidade e tomar uma posição, e a katharsis, por sua vez, concretiza o processo de identificação, possibilitando ao leitor adquirir uma nova postura diante de si mesmo e do mundo que o rodeia.

Dessa forma, o trabalho desenvolvido através dos roteiros de leitura, baseado na metodologia exposta por Juracy Assmann Saraiva, contempla as etapas explicitadas anteriormente. A leitura foi organizada de forma sistemática para que o aluno se transformasse em um leitor qualificado da obra machadiana e a desenvolvesse além do texto, preenchendo as lacunas deixadas pelo escritor. As etapas do trabalho também possibilitaram ao leitor em formação a apreciação do texto literário como recurso para compreender a realidade e a condição humana, bem como a reflexão sobre essas questões.

Ressalta-se que a conquista do leitor partiu da análise de narrativas curtas, ou seja, da apreciação de contos e essa perspectiva de formação de leitores será explorada no tópico seguinte.

\section{A leitura de contos como alternativa na formação de leitores}

Neste mundo globalizado em que o desejo do acesso a bens materiais sufoca valores essenciais, em que tudo é passageiro e em que as inovações tecnológicas atraem o olhar, o professor precisa introduzir seus alunos no universo mágico da literatura, de forma criativa e prazerosa, para que, no futuro, eles possam alçar vôos maiores. Conforme Bordini e Aguiar

A atividade do leitor de literatura se exprime pela reconstrução, a partir da linguagem, de todo o universo simbólico que as palavras encerram e pela concretização desse universo com base nas vivências pessoais do sujeito. A literatura, desse modo, se torna uma reserva de vida paralela, onde o leitor encontra o que não pode ou não sabe experimentar na realidade. É por 
essa característica que tem sido acusada, ao longo dos tempos, de alienante, escapista e corruptora, mas é também graças é ela que a obra literária captura o seu leitor e o prende a si mesmo por ampliar suas fronteiras existenciais sem oferecer os riscos da aventura real.

(BORDINI e AGUIAR, 1988, p.15)

Para que a obra literária possa capturar o leitor, é necessário que este seja apresentado a ela de forma adequada. Os contos, por serem mais curtos e propiciarem uma leitura mais rápida, viabilizam sua leitura integral numa só aula, o que permitirá ao professor realizar uma leitura compartilhada com os alunos. O acesso a contos pode constituir uma alternativa viável para formar leitores apaixonados se o professor investir nos aspectos que estabelecem uma crítica da realidade e na exposição dos recursos da linguagem.

Perrone-Moisés questiona as orientações que o ensino da literatura assume na escola perguntando: "Como é possível formar novos leitores e novos escritores sem o conhecimento da literatura do passado?" (PERRONE-MOISÉS, 2005, p.345) Ela coloca em questão o fato de, no Ensino Médio, os textos literários serem tratados como qualquer outro gênero textual, não lhes sendo dado o devido valor. Afirma também que o "desprestígio progressivo do ensino da alta literatura, ou da literatura difícil, representada pelos textos canônicos ocidentais, é um fato histórico universal,” (PERRONE-MOISÉS, 2005, p.345) apontando razões para esse desprestígio:

Vivemos numa época de informação coletiva e rápida, e a leitura literária é uma atividade solitária, lenta e que, para ser bem feita, precisa ser apreendida. Respostas simples às grandes questões filosóficas e existenciais passaram a ser buscadas, por aqueles que ainda lêem, em manuais de auto-ajuda, mais reconfortantes do que os textos literários.

(PERRONE- MOISÉS, 2005, p.346)

A partir dessa afirmação de Perrone-Moisés depreende-se a importância de trabalhar com contos canônicos no Ensino Médio, pois dessa forma, além do aluno ter a oportunidade de conhecer obras de grandes autores e experimentar a katharsis ${ }^{2}$, os alunos terão a oportunidade de lê-los junto com seus colegas e com seu professor, que esclarecerá, no momento da leitura, os aspectos que expõem a narrativa como um processo em construção.

Juracy Assmann Saraiva apresenta no artigo intitulado A sedução das narrativas aplicada ao estudo de contos machadianos o embasamento teórico e uma proposta metodológica voltada para o ensino da literatura, exemplificando-a por meio de contos de

\footnotetext{
${ }^{2} \mathrm{Na}$ katharsis "o espectador pode ser afetado pelo que se representa, identificar-se com as pessoas em ação, dar assim livre curso às próprias paixões despertadas e sentir-se aliviado por sua descarga prazerosa, como se participasse de uma cura (katharsis). Esta descoberta e justificação do prazer catártico, com a qual Aristóteles corrigia o "mecanismo do efeito direto", sobre o qual Platão apoiara sua condenação da arte, é por certo a herança mais provocante da teoria antiga do poético. Dela se poderia dizer (o que a estética psicanalítica apenas confirmou) que "nos deu a única resposta até hoje convincente sobre a questão de por que a contemplação do mais trágico acontecimento nos causa o mais profundo prazer" (JAUSS, 1979, p.87).
} 
Machado de Assis. Ao evidenciar a aproximação possível dos alunos com a obra machadiana, o artigo também constitui importante base teórica para olhar criticamente as propostas desenvolvidas no que tange ao trabalho com esses textos e também para orientar os docentes no desenvolvimento das atividades.

Em relação à leitura de Machado de Assis no Ensino Médio, Saraiva constata que a maioria dos alunos, mesmo não conhecendo as obras do autor, rotula-as depreciativamente, estabelecendo uma espécie de rejeição:

Outra barreira que o professor enfrenta são os preconceitos ou pré-conceitos que "aderem" a autores ou obras, provocando uma rejeição que se antecipa a sua leitura. Nesse último caso, inclui-se Joaquim Maria Machado de Assis: raros são os alunos que, cursando a $1 .^{\mathrm{a}}$ ou a 2. ${ }^{\mathrm{a}}$ série do Ensino Médio, já leram algum de seus textos; entretanto, muitos dizem ser ele um autor "difícil e chato", ainda que não tenham tido acesso às suas obras, enquanto outros não têm qualquer informação sobre o escritor brasileiro.

(SARAIVA, 2007, p. 173)

Saraiva salienta que o preconceito em relação à obra machadiana, no Ensino Médio, precisa ser superado. Segundo a autora, a leitura das obras do escritor em sala de aula é plenamente justificável, quando se pensa na relevância da figura machadiana para as letras brasileiras e na contemporaneidade dos seus escritos, característica essa que se dá através da apresentação de aspectos peculiares a todos os seres humanos. Ela afirma:

\footnotetext{
Esse posicionamento se justifica pela importância de Machado no cenário da literatura brasileira e pelo fato de que suas narrativas, ainda que escritas no século XIX, podem provocar o diálogo com leitores contemporâneos, porque transpõem uma dimensão do humano que transcende um tempo e um espaço determinados.
}

(SARAIVA, 2007, p. 173-174)

A autora também orienta para o modo de iniciação do aluno na obra de Machado, afirmando que ele deve começar a leitura pelos contos. Nesse sentido, a leitura de Dom Casmurro não é recomendada inicialmente devido ao fato de o aluno adolescente não estar preparado para aceitar as características principais do romance, tais como a questão da dúvida e do ciúme:

Exigir, por exemplo, que adolescentes leiam Dom Casmurro é correr o risco de transformar o texto literário em objeto de rejeição e não de sedução. O processo de composição desse romance prevê um leitor capaz de aceitar a ambigüidade como fundamento do relato e de dar tanta importância à história quanto às reflexões sobre $o$ processo da narração. Simultaneamente, o tema do ciúme, exposto sob a ótica de um homem afetivamente fracassado e afastado do convívio social, não encontra ressonância na fantasia dos jovens que crêem na realização amorosa e nela buscam a concretização de um sentimento idealizado.

A partir dessa ótica, sugere-se que o professor de Língua Portuguesa explore contos de Machado de Assis, deixando os romances para uma etapa posterior.

(SARAIVA, 2007, p. 174) 
Saraiva expõe, também, que o professor pode ter acesso às diferentes temáticas abordadas por Machado de Assis, cuja atualidade é evidente como se constata em Pai contra mãe e em Confissões de uma viúva moça e Singular ocorrência. No primeiro conto, desnudase "a brutalidade humana, cuja manifestação não se restringe às práticas do regime escravocrata e que desconhece até mesmo o direito à vida, e a luta pela sobrevivência que expõem os mais primitivos instintos do homem"; nos outros dois, projeta-se "a vida das mulheres, seus desejos e afetos, as frustrações e os preconceitos que sofrem" (SARAIVA, 2007, p. 176).

Na obra machadiana, o professor possui variadas opções de textos para o trabalho em sala de aula, temas distintos, instigantes e atuais, capazes de promover a reflexão sobre a condição humana.

Por meio da análise de Verba testamentária, Juracy Saraiva detalha as etapas que possibilitam ao aluno interagir com o texto literário: leitura compreensiva, leitura analítica, leitura interpretativa e transferência e aplicação da leitura.

Antes de iniciar o trabalho com a narrativa, o professor, segundo Saraiva, deve incentivar o aluno para a leitura, pois "a atitude negativa de alunos diante da proposição da leitura de textos literários pode ser minimizada ou, até mesmo, extinta, sempre que o docente provoca o interesse ou a curiosidade em relação à obra a ser lida”. (SARAIVA, 2007, p. 180).

A etapa de compreensão, de acordo com Saraiva, deve contar com a "leitura integral" do conto. O professor, ao efetuar a leitura, deve proferir questionamentos que induzam os alunos a entenderem o texto, explicar as passagens em que eles apresentam dificuldades, bem como esclarecer o significado de palavras desconhecidas por eles. Ao final dessa etapa, "os alunos se sentem aptos a responder à pergunta: O que o texto conta?" (SARAIVA, 2007, p. $180)$.

Na leitura analítica efetua-se o estudo dos aspectos composicionais da narrativa, tais como o da sequencialidade das ações, das personagens e do processo de comunicação. Assim, a autora esclarece:

Como "Verba testamentária" é um texto narrativo, a análise da estrutura das ações, a caracterização das personagens, os dados da localização tempo-espacial devem somar-se à análise do processo de comunicação do narrador, das posições ideológicas manifestadas por ele, e do uso das modalidades de discurso - responsáveis por estabelecer a proximidade ou o distanciamento diante do narrado - e do tratamento dispensado à temporalidade.

(SARAIVA, 2007, p. 181)

Nessa etapa, mediante a análise dos componentes da narrativa, responde-se a seguinte questão: “Como o texto diz aquilo que diz?” (SARAIVA, 2007, p. 181). 
A leitura interpretativa consiste no estabelecimento de relações entre a leitura compreensiva e a leitura analítica de forma a confirmar ou não os resultados da primeira. $\mathrm{O}$ leitor, nessa etapa, ao interpretar, estabelece ligações entre o texto lido e a realidade que o cerca. Nesse sentido, de acordo com Saraiva, "ao estabelecer a relação entre texto e contexto, o leitor responde à pergunta - Qual é o sentido do texto? -, mas, simultaneamente, encontra respostas para questões que o atingem em seu cotidiano" (2007, p. 182). A atividade de interpretação também contribui para que o aluno, ao ler criticamente, estabeleça elos com a realidade, manifestando-se através do seu texto. A leitura interpretativa "abre as portas" para a atividade de transferência e aplicação da leitura.

Na última etapa, o aluno é conduzido à produção textual. Cabe ao professor estimulálo a produzir narrativas de acordo com a temática explorada pelo texto lido. Após a revisão do professor, o aluno pode apresentar o texto a seus colegas. Através do trabalho com contos, o professor também pode estimular o estabelecimento de relações desses com outras produções, promovendo assim a transferência e a aplicação da leitura. Essa metodologia está expressa na seguinte passagem do artigo:

Com a finalidade de completar a recepção, recomenda-se que o professor traga exemplos de outras narrativas da tradição oral ou literária que se aproximem, sob o aspecto temático, do conto de Machado. Igualmente, que busque complementar a interpretação com dados factuais da biografia do autor e do contexto estético-histórico-cultural de sua produção, para relacionálos aos valores e ideologias expressos no conto. Essa leitura contextualizada constitui uma motivação para o reconhecimento da literatura como instituição sistêmica, já que os textos literários se articulam entre si e dialogam com outras manifestações culturais, expressas ou não por meio da palavra.

As atividades de transferência e aplicação, além de garantirem o espaço da produção escrita e oral do aluno, visam responder às seguintes perguntas: Com que textos é possível relacionar este texto? Que diálogo há entre o texto e o contexto estético-histórico-cultural do momento de sua produção?

(SARAIVA, 2007, p. 182-183)

\section{Uma proposta de roteiro de leitura dos contos para o Ensino Médio}

Para avaliar a dificuldade de trabalhar com as obras de Machado de Assis no Ensino Médio, realizou-se em seis turmas de $1^{\circ}$ e $2^{\circ}$ anos da Escola Estadual de Ensino Médio Bernardo Vieira de Mello, em Esteio, nos anos de 2007 e de 2008, um projeto intitulado Redescobrindo o prazer de ler contos. Este projeto consistiu na aplicação de leitura e exploração dos contos machadianos: A cartomante e Pai contra mãe.

Os objetivos gerais deste trabalho foram comprovar que os contos de Machado de Assis podem ser trabalhados de forma prazerosa em turmas de Ensino Médio e incentivar o gosto pela leitura e pela escrita por meio do trabalho desenvolvido com roteiros de leitura. 
Os objetivos específicos consistiram em:

- ouvir, ler e compreender os contos em estudo;

- perceber a sequencialidade das ações na história e a diferença entre história e discurso;

- analisar as personagens observando o ponto de vista do narrador e a visão que uma personagem apresenta da outra;

- identificar informantes e índices que dão verossimilhança às narrativas;

- observar o vocabulário empregado e a função das figuras de linguagem utilizadas pelos autores nos contos;

- relacionar os episódios relatados nos contos à vida real, observando a atualidade dos assuntos neles explorados;

- comparar os contos: A cartomante, de Machado de Assis com o Tílburi de praça, de Raul Pompéia e Pai contra mãe com O caso da vara, ambos de Machado de Assis;

- reconhecer os contos como um gênero do modo narrativo e diferenciá-los de outros textos que também fazem parte deste modo.

No roteiro de leitura referente ao conto $A$ cartomante, aplicado em duas turmas de $1^{\circ}$ ano e duas turmas de $2^{\circ}$ ano, em 2007, a atividade introdutória de recepção ao texto consistiu na análise, em pequenos grupos, de anúncios de cartomantes retirados de jornais e de revistas e de panfletos do mesmo tipo distribuídos nas ruas da cidade e da discussão sobre a forma com que os anúncios são elaborados para influenciar as pessoas. Depois da atividade introdutória foi realizada a leitura oral do conto, na qual a professora foi explicando aos alunos os aspectos composicionais da narrativa e localizando com os alunos os informantes espaciais e temporais e os índices. Ao final da leitura, a professora pediu aos alunos que lessem novamente o conto, silenciosamente, e observassem a sequencialidade das ações na história e esclareceu a diferença entre história e discurso.

Dentre as atividades propostas no roteiro, destacaram-se a análise das personagens da narrativa, observando o ponto de vista do narrador e a visão que cada personagem apresentava da outra; a identificação de informantes e índices que davam verossimilhança à narrativa; a observação do vocabulário empregado e a função das figuras de linguagem; a redação de um texto argumentativo defendendo ou acusando uma das personagens da narrativa; a redação de um texto narrativo baseado num anúncio de cartomante.

Após a realização das atividades propostas no roteiro, foi lido com os alunos o conto Tílburi de praça, de Raul Pompéia e foram desenvolvidas atividades de comparação entre os dois contos, uma vez que ambos apresentam um triângulo amoroso e o tema da traição, além de se passarem na mesma época. No final do trabalho com esses contos, os alunos escolheram 
uma cena de um dos contos para dramatizarem em grupos; pesquisaram a biografia e a obra dos autores na internet e também o contexto sócio-cultural da época em que foram escritos os contos em estudo.

No roteiro de leitura de Pai contra mãe, aplicado em duas turmas de $2^{\mathrm{a}}$ ano, em 2008 , a atividade introdutória à recepção do texto consistiu na apresentação de transparências com telas representando a escravidão no Brasil colônia, pintadas por Debret, a análise delas em pequenos grupos e um debate sobre as imagens nelas apresentadas. Algumas telas retratavam castigos aplicados aos negros na época da escravidão e, por isso, tinham relação com o conto que seria lido a seguir. Após a análise das telas foi realizada a leitura oral do conto e as explicações da professora sobre os aspectos composicionais da narrativa.

As atividades que se destacaram no roteiro foram as de compreensão textual e de interpretação, as de análise das estratégias discursivas adotadas por Machado de Assis, tais como a ironia e a metáfora, procurando captar o que não está dito claramente no conto, a identificação dos tipos de discurso presentes no texto, a análise das relações entre as personagens, o estabelecimento de relações entre os nomes de ruas e o significado do texto. Foram realizadas também duas produções textuais, uma questionando o motivo da escolha do título Pai contra mãe por Machado e outra que consistiu num texto argumentativo para avaliar o posicionamento de Cândido Neves. Ao término das atividades previstas no roteiro, foi feita a leitura oral e silenciosa de outro conto de Machado de Assis que também retrata a escravidão, $O$ caso da vara, e a comparação entre os dois. Após as atividades comparativas foi feita a relação com outros textos, a contextualização do autor e da obra e sua relação com outras obras.

Os resultados desse trabalho comprovam que os contos de Machado de Assis permitem relações intertextuais com outras produções artísticas e o confronto das situações vivenciadas pelas personagens com o mundo atual. Além disso, apresentam histórias envolventes, com riqueza de significados.

A avaliação do projeto aconteceu de forma contínua e sistemática durante o desenvolvimento do mesmo, observando-se alguns critérios, tais como: a participação e envolvimento dos alunos nas atividades propostas; a contribuição com idéias, atitudes e questionamentos. Além disso, os alunos também realizaram uma avaliação do projeto.

Como resultado dessa experiência, expõem-se os gráficos abaixo que registram a autoavaliação dos alunos quanto à leitura dos contos e seu progresso na leitura, na recepção dos textos e na aplicação da leitura. 
Auto-Avaliação dos Alunos

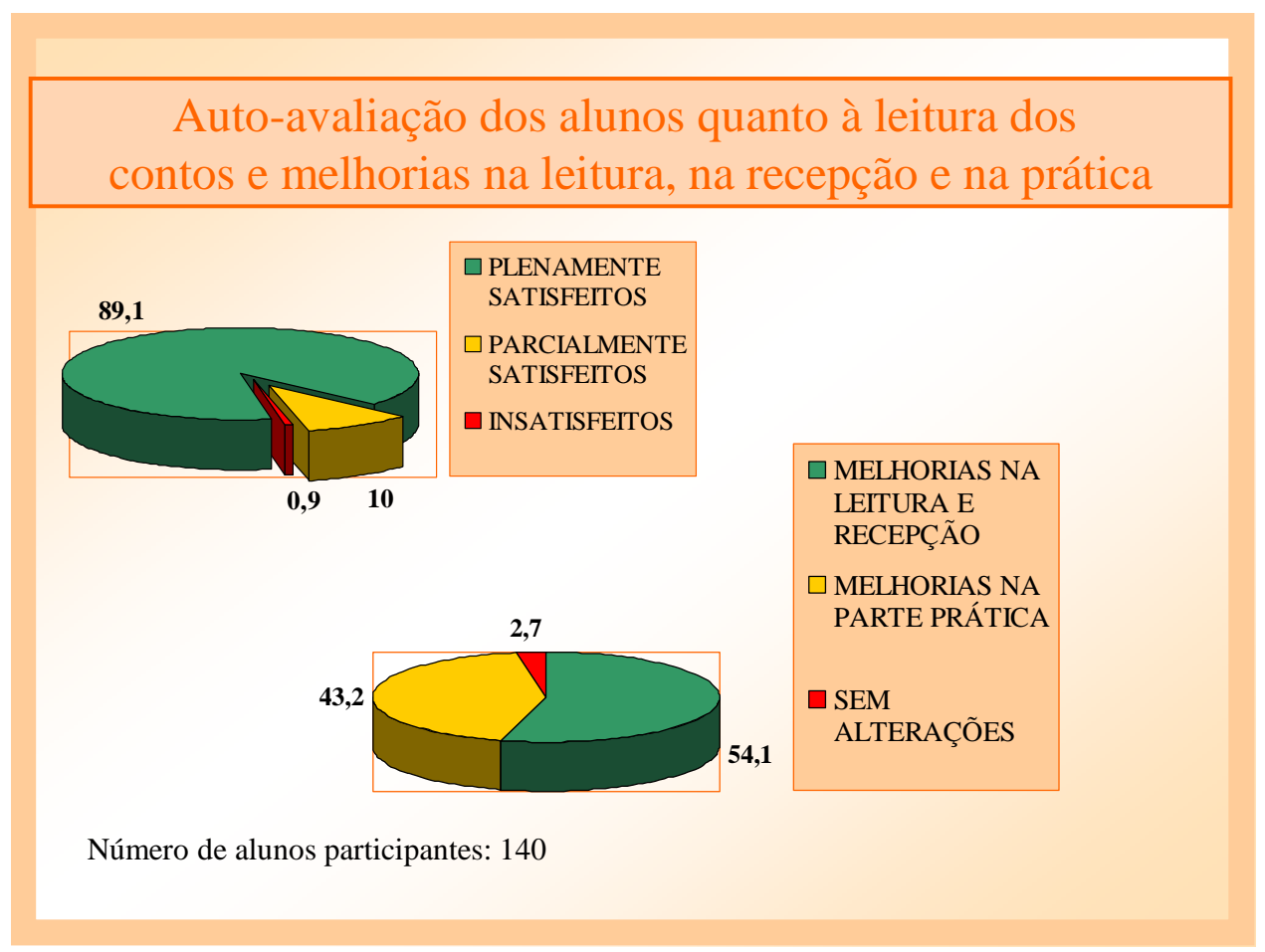

Figura 1 - Auto-Avaliação dos Alunos ${ }^{3}$.

Pelo gráfico acima e pelos depoimentos dos alunos que vivenciaram a situação, comprova-se o sucesso da experiência realizada. Cada um dos alunos recebeu um questionário contendo enunciados a serem completados por eles. Dessa forma, perguntou-se aos alunos se eles haviam considerado boa ou ruim a experiência e solicitou-se a justificativa dessa escolha. Todos os alunos relataram a leitura como uma experiência significativa e positiva. Eis alguns dos depoimentos sobre a leitura dos contos:

- “... eu nunca tinha lido uma coisa tão legal”. (Turma 101)

• “... não costumava ler, os textos incentivaram minha leitura”. (Turma 101)

• “... são coisas que a gente não se interessava e agora garanto que todos gostam". (Turma 101)

- “... depois que li esses contos fiquei mais esperta, inteligente”. (Turma 102)

• “... eles envolvem as pessoas que estão lendo”. (Turma 102)

- “... eu não ligava muito para esses tipos de coisas e agora me interessei mais”. (Turma 202)

• “... aprendi a dar valor à leitura, antes eu já gostava, agora eu amo ler”. ( Turma 202)

- “... nós aprendemos interpretação e a ler”. (Turma 202)

- “... pude aprender muita coisa sobre análise de texto”. (Turma 202)

\footnotetext{
${ }^{3}$ Trabalho apresentado nos seguintes eventos: Feira de Iniciação Científica e Salão de Extensão (FICSE), 2008 e Salão de Iniciação Científica da UFRGS, 2009.
} 
- “... foi super interessante pois mostrou o jeito verdadeiro das pessoas, de como elas se portam”. (Turma 202)

- “... a leitura dos contos foi interessante porque nos faz pensar”. (Turma 202)

- “... a leitura dos contos foi legal. O conto Pai contra Mãe explica como viviam os escravos". (Turma 202)

- “... a leitura dos contos foi muito boa. Gostei do conto Pai contra Mãe porque conta as escolhas que temos de fazer na vida". (Turma 202)

- “... a leitura dos contos foi muito difícil porque era a atividade em que era preciso pensar". (Turma 202)

Os alunos também forma questionados sobre o que aprenderam através dos roteiros. Assim, eles responderam ao questionamento: Com a leitura de ambos os contos e as atividades de interpretação dos mesmos aprendi que:

- “... todos os contos exigem uma atenção muito grande e, que, para realmente entender, devo "entrar" dentro do conto". (Turma 101)

- "... temos que dizer sempre a verdade e termos confiança um no outro e em si mesmo". (Turma 101)

- “... que se deve pensar bem no que vai fazer para não sofrer as conseqüências depois". (Turma 101)

• “... tenho que ler mais para aperfeiçoar minha interpretação”. (Turma 101)

- “... aprendi muitas coisas com esses trabalhos, aprendi em Português e coisas para minha vida". (Turma 102)

- “... tem como fazer um conto de época antiga com realidades de agora e muito diversificado, que dá vontade de ler”. (Turma 102)

- “... a importância da leitura na vida das pessoas, ela é essencial”. (Turma 201)

- “... é importante conhecer melhor grandes obras literárias”. (Turma 201)

- “... é sempre bom aprender a ler, ainda mais quando são essas histórias parecidas com a vida real". (Turma 202)

De posse desses resultados, percebe-se o quanto os alunos valorizaram o trabalho com roteiros de leitura dos contos machadianos e que se o professor optar por contos, ele terá à disposição variadas opções de textos para o trabalho em sala de aula, com temas distintos, instigantes e atuais, capazes de promover a reflexão sobre a condição humana.

\section{Considerações finais}

O projeto atingiu seu objetivo, contribuindo de forma significativa na formação de leitores. O grupo apresentou interesse em conhecer outras obras de Machado de Assis e a melhoria na escrita, demonstrando, assim, que os contos do autor são adequados para alunos do Ensino Médio. Este trabalho constituiu uma forma de iniciação dos alunos no mundo literário, no universo das narrativas mais complexas, como salienta Leyla Perrone Moises 
(2005, p.347), escritas há muito tempo, porém ricas na forma estética e intelectual. A magia da leitura comprovou-se ao perceber os olhos pasmos daqueles alunos diante das comprovações de atualidade dos textos, da constatação de situações que ainda são vivenciadas pelo ser humano, de comportamentos e atitudes ainda presentes nas relações humanas, tais como a mentira, a traição e a crueldade.

Depois de estudarem dois anos contos de Machado de Assis e de outros autores e de escreverem muitas produções textuais, os alunos começaram a utilizar técnicas de escrita do estilo de Machado, tais como: a utilização de nomes de ruas reais para dar verossimilhança à narrativa e a inclusão de objetos e de elementos da espacialidade como índices e informantes em suas produções. Os alunos começaram a ler mais contos e até romances, a escrever textos com mais prazer e comentar suas leituras. Algumas alunas elegeram Machado de Assis como seu escritor preferido e melhoraram ainda mais sua escrita, após o trabalho intenso de leitura e exploração de contos realizado nestes dois anos.

Todos os alunos dessas turmas participaram do Concurso de Narrativas de Natal de Dois Irmãos e três alunas dos segundos anos ganharam o $1^{\mathrm{a}}$, o $2^{\mathrm{a}}$ e o $3^{\mathrm{o}}$ lugar na categoria alunos de Ensino Médio, no ano de 2008. No dia em que receberam a premiação, acompanhados de suas famílias, uma das alunas, com lágrimas escorrendo pela face, comentou que nunca imaginou viver algo tão lindo. Disse que era como se estivesse vivendo um sonho ter o seu texto publicado num livro e estar ali, naquele lugar repleto da magia do Natal, recebendo o troféu com a sua família.

É muito gratificante tanto para o professor quanto para os alunos trabalhar com textos literários, pois a função humanizadora da literatura transforma a vida das pessoas e faz acreditar que é possível melhorar a educação.

\section{Referências}

BORDINI, Maria da Glória; AGUIAR, Vera Teixeira de. "Leitura da literatura". In: BORDINI, Maria da Glória; AGUIAR, Vera Teixeira de. Literatura: a formação do leitor - alternativas metodológicas. Porto Alegre: Mercado Aberto, 1988, p.09-17.

CANDIDO, Antonio. "O direito à literatura". In: CANDIDO, Antonio. Vários Escritos. São Paulo; Rio de Janeiro: Duas cidades: Ouro sobre azul. 4. ed., 2004, p.169-192.

FREITAG, Bárbara; MOTTA, Valéria Rodrigues; COSTA, Wanderly Ferreira da. "O livro didático em questão". São Paulo: Cortez/Autores Associados, 1989. Coleção educação contemporânea.

JAUSS, Hans Robert; coordenação e tradução de Luiz Costa Lima. "O prazer estético e as experiências fundamentais da poiesis, aisthesis e katharsis". In: JAUSS, Hans Robert...et al A literatura e o leitor: textos de estética da recepção. Rio de Janeiro, Paz e Terra, 1979, p.85-104. 
PERRONE-MOISES, Leyla. Estud. av. [online]. 2005, vol.19, n.55, pp. 335-348. Por amor à arte. Disponível em http://www.scielo.br/scielo.php?script=sci_arttext\&pid=S0103-4014200 5000300025 in 11 de setembro de 2010.

SARAIVA, Juracy Ignez Assmann. "A sedução das narrativas aplicada ao estudo de contos machadianos". In: BARBOSA, Valéria Koch; SCHNEIDER, Simone Daise (Orgs.). Linguagem, sociedade e interação: reflexões teórico-práticas. Novo Hamburgo: Feevale, 2007, p.171-184.

(Org.). Literatura e alfabetização: do plano do choro ao plano da ação. Porto Alegre: Artmed, 2001.

; MÜGGE, Ernani. Literatura na Escola: propostas para o ensino fundamental. Porto Alegre: Artmed, 2006. 